\title{
Hydrodynamic Characteristics of the Propeller-Rudder Interaction by RANS Solver
}

\author{
Seyed Morteza Javadpour ${ }^{1}$, Ali Eskafi Noghani ${ }^{2}$, Hassan Ghassemi ${ }^{2, *}$, David Molyneux ${ }^{3}$ \\ ${ }^{1}$ Department of Mechanical Engineering, University of Gonabad, Iran \\ ${ }^{2}$ Department of Maritime Engineering, Amirkabir University of Technology, Tehran, Iran \\ ${ }^{3}$ Department of Ocean and Naval Engineering, Memorial University of Newfoundland, St. John's, Canada \\ *Corresponding author: gasemi@aut.ac.ir \\ Received January 03, 2019; Revised February 16, 2019; Accepted February 24, 2019
}

\begin{abstract}
This paper is presented the interaction between propeller and rudder at different operating conditions by using ANSYS-Fluent software. A moving reference frame (MRF) method is applied and the flow equations are solved using Reynolds-Averaged Navier-Stokes (RANS) method and the K- $\omega$ SST turbulent model. The propeller is selected VP1304 and rudder is spade type with NACA0015 section. Hydrodynamic characteristics of the propeller with and without rudder, effect of rudder on the propeller performance, rudder lift and drag, pressure and velocity contour are presented discussed. The results show that the rudder effect on the propeller is small while the propeller on the lift and drag of the rudder may be significant.
\end{abstract}

Keywords: propeller VP1304, spade rudder, hydrodynamic characteristics, lift and drag coefficients

Cite This Article: Seyed Morteza Javadpour, Ali Eskafi Noghani, Hassan Ghassemi, and David Molyneux, "Hydrodynamic Characteristics of the Propeller-Rudder Interaction by RANS Solver." American Journal of Mechanical Engineering, vol. 7, no. 1 (2019): 35-40. doi: 10.12691/ajme-7-1-4.

\section{Introduction}

Propeller and rudder are located behind the ship where the flow into the propeller is non-uniform and unsteady. Propeller generates thrust to run the ship. Rudder is for making maneuvering the ship. Both of them are lifting bodies like wing and hydrofoil. Working of the numerical methods for the propeller, rudder behind the ship is very complicated because of they are operating in the wake field. Many numerical methods have been done for the propeller_based on RANS method since 1990. The probability of solving the Navier-Stokes equations based on RANS method was presented [1]. The propeller geometry with flow properties and the propeller solution using RANS method determined [2,3].

Rudder is a control surface and is employed for the ship to maneuver the ship. A comprehensive book for the marine rudder and control surface is published by Moland $\&$ Turnock [4]. The flow in periphery of the rudder using numerical analysis was studied [5]. The hydrodynamic response of a 3D model on a hydrofoil using boundary element method with cavitation consideration investigated [6]. An idea to improve rudder performance by testing a scaled model proposed [7]. Interactions between the rudder and propeller in low velocities using two high precision meshes presented [8]. A four-blade propeller together with a rudder with NACA0020 cross-section was studied [9]. The hull-propeller-rudder interactions of twin-screw carried out by CFD [10]. The unsteady propeller and rudder interaction numerically investigated [11]. Ghassemi et al carried out comprehensively on different marine propulsors using computational fluid dynamics and boundary element method (CFD and BEM). They investigated on the hydrodynamic characteristics of the propeller-rudder system (PRS) and AZIPOD $[12,13,14]$. They also prepared a comprehensive HPSOP code for hydrodynamic multidisciplinary optimization of a ship and its propeller $[15,16,17,18]$.

In this article, the numerical results of the propeller and rudder interactions are presented. The rudder angles are shown on the propeller performance. The following sections are organized as follows: Results of the hydrodynamic characteristics of the propeller is validated in Sec. 2. The propeller and rudder interaction are presented and discussed in Sec. 3. Finally, the conclusions are given in Sec. 5 .

\section{Hydrodynamic Characterizes of the Propeller}

In that experiment the propeller was tested in conditions corresponding to the tow test, with shaft immersion equal to 1.5 of propeller diameter D. In the resent research, to obtain open water propeller characteristics the simulation calculations were performed for the following values of the advance coefficient $\mathrm{J}=0.6,0.8,1.0,1.2$ and 1.4. The range of analysis usually includes the design operation point, i.e. the parameter for which the propeller has been designed. The results of experimental and numerical 
examination of the propeller are shown in the form of dimensionless thrust and torque coefficients as functions of rotational speed $\mathrm{n}$ and diameter $D$ of the propeller, and water density $\rho$.

The propeller thrust coefficient:

$$
K_{T}=\frac{T}{\rho n^{2} D^{4}} .
$$

The propeller torque coefficient:

$$
K_{Q}=\frac{Q}{\rho n^{2} D^{5}}
$$

Speed (advance) coefficient:

$$
J=\frac{V_{a}}{n \cdot D}
$$

Propeller efficiency:

$$
\eta=\frac{J}{2 \pi} \cdot \frac{K_{T}}{K_{Q}}
$$

where $\mathrm{T}$ is thrust $[\mathrm{N}], \mathrm{Q}$ is torque $[\mathrm{Nm}]$ and $\mathrm{V}_{\mathrm{A}}$ is advance speed $\left[\mathrm{ms}^{-1}\right]$.

The propeller is tested in the fluid at $15.6^{\circ} \mathrm{C}$ that density and kinematic viscosity are $999 \mathrm{~kg} / \mathrm{m}^{3}$ and $1.124 \mathrm{e}-6 \mathrm{~m}^{2} / \mathrm{s}$, respectively.

This paper is presented the hydrodynamic performance of the propeller-rudder behind the ship by using ANSYSFluent software. The propeller is VP1304 (or PPTC). The main dimensions are given in Table 1.

Table 1. Main dimensions of the VP1304 propeller

\begin{tabular}{|l|c|}
\hline Parameter & Value \\
\hline Diameter (D) [m] & 0.250 \\
\hline Pitch ratio at r/R=0.7 (P/D) [-] & 1.635 \\
\hline Expanded area ratio (EAR) [-] & 0.779 \\
\hline Chord length at r/R=0.7 (c/D) [-] & 0.1047 \\
\hline Skew angle [deg] & 18.84 \\
\hline Hub ratio $\left(\mathrm{r}_{\mathrm{h}} / \mathrm{R}\right)[-]$ & 0.300 \\
\hline Number of blade $(\mathrm{Z}) \quad[-]$ & 5 \\
\hline Rotation direction & $\mathrm{CW}$ \\
\hline Propeller type & $\mathrm{CPP}$ \\
\hline
\end{tabular}

\subsection{Validation for Propeller Results in Open Water}

The propeller was designed in Solidworks software according to the reported information by SVA. In this study, the 2012 version of this software and Ansys collection software including ICEM and Design Modeler were applied for geometrical designs. It should be noted that, in numerical analysis, the CAD model should be simplified and the complications should be avoided. Moreover, sharp edges should be avoided designing the propeller. Figure 1 shows the CAD model of the propeller in Solidworks.

In this study, the MRF is employed for simulation. Solution field and the moving frame were designed in periphery of the propeller. Computational domain of the propeller is shown in Figure 2. For numerical modeling, the solution field should be divided in finite volumes. So, a proper mesh should be applied to the model. In this study, the meshing was done using ANSYS-ICEM software. Figure 3 presents the Meshes of the propeller and its moving frame.

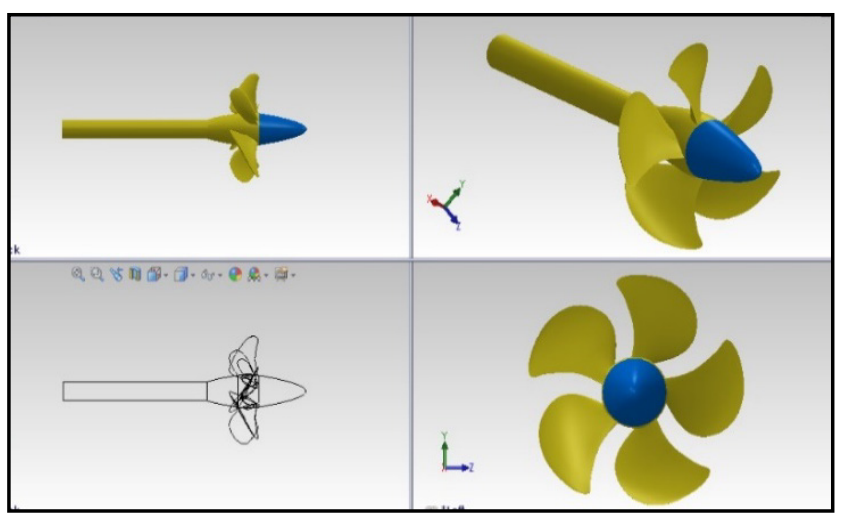

Figure 1. CAD model of the propeller in Solidworks

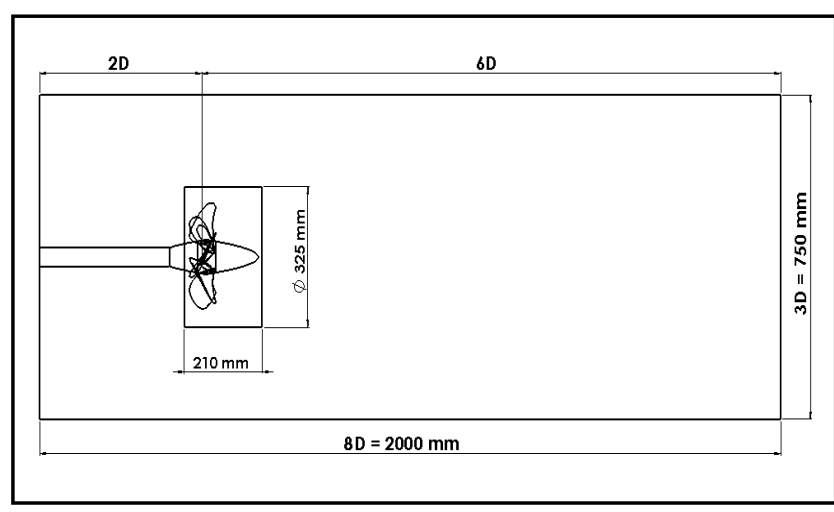

Figure 2. Computational domain of the propeller

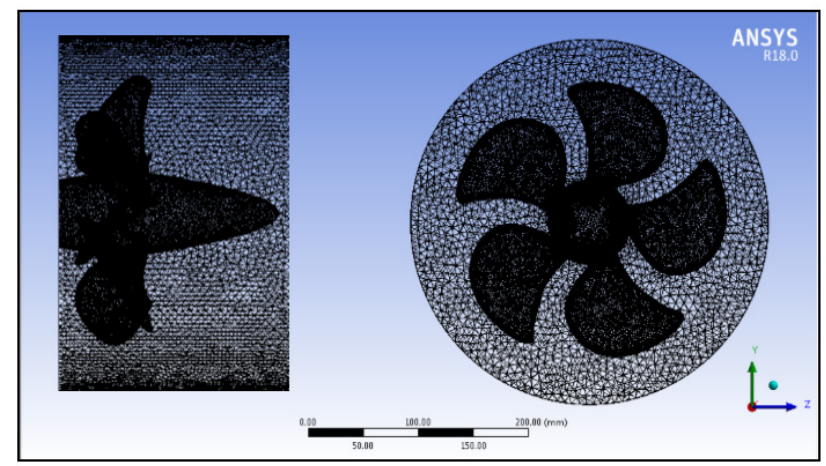

Figure 3. Meshes of the propeller and its moving frame

The number of nodes is 743168 . The applied mesh was hybrid type. To improve the results and solving time, mainly prism type meshes was applied although wedge and pyramid type meshes were also applied locally. Growing rate was considered 1.2 for meshes. Figure 4 presents investigations on independency from meshes for the thrust coefficient. The problem was solved using four different meshes and according to the required precision and solution cost, the mesh with 3127110 elements is selected. 


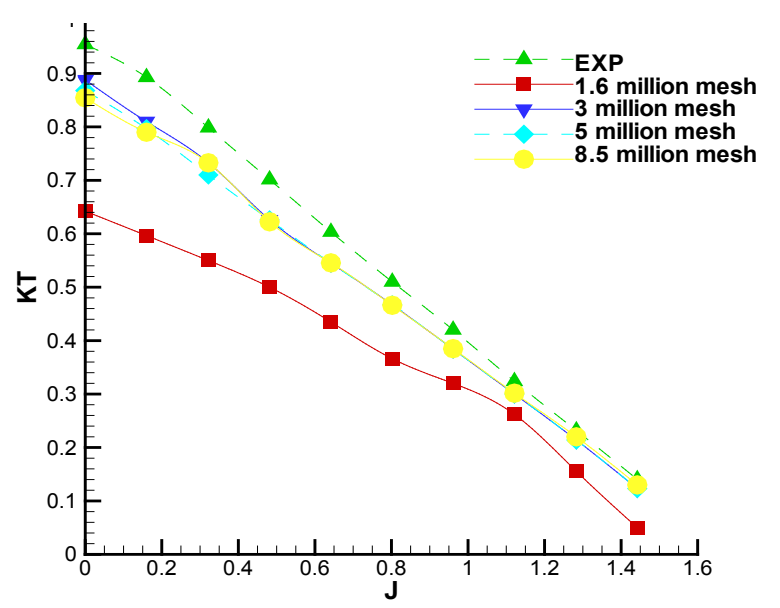

Figure 4. Investigation on independency from meshes in various advanced rates

After finding the mesh numbers and the results of thrust coefficient, the numerical method extended to calculate the hydrodynamic characteristics of the propeller in open-water condition. Figure 5 show the comparison of the numerical results and experimental data of the open-water propeller characteristics. The maximum relative error for the thrust coefficient is less than $10 \%$ and for the torque is less than $9 \%$ that are occurred at low advance.

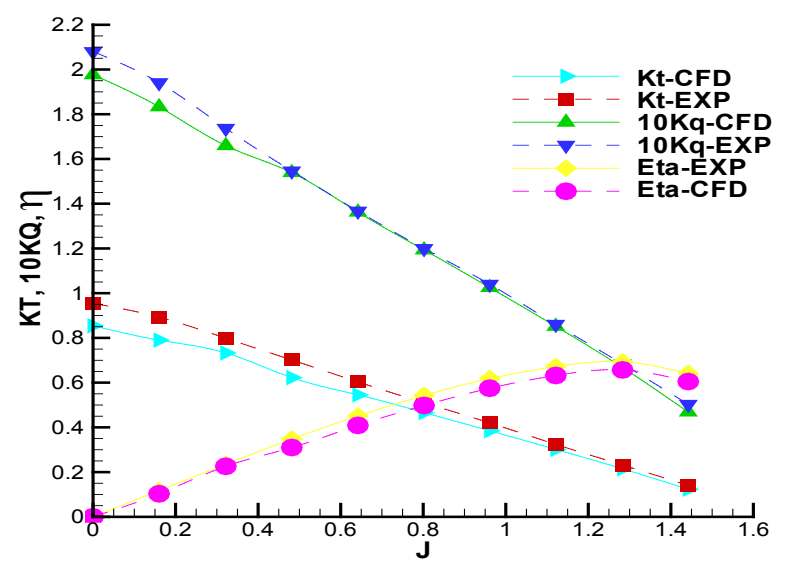

Figure 5. Comparison of the numerical results and experimental data

\section{Results of the Propeller-Rudder Interaction}

A spade rudder is selected for the ship with section of the NACA0015. The selected rudder has $276 \mathrm{~mm}$ height (or span) and $194 \mathrm{~mm}$ chord (chord at root $270 \mathrm{~mm}$ and at tip is 118). Aspect ratio and taper ratio are 1.4 and 0.42 , respectively. Figure 6 is presented the propeller and rudder.

The lift (lateral force) and drag of the rudder coefficient are defend as

$$
\begin{aligned}
C_{L} & =\frac{L}{0.5 \rho A_{R} U^{2}} \\
C_{D} & =\frac{D}{0.5 \rho A_{R} U^{2}}
\end{aligned}
$$

where $L$ and $D$ are lift [N] and drag [N], $U$ is inflow velocity to the rudder $\left[\mathrm{ms}^{-1}\right]$; and $A_{R}$ is the rudder area.

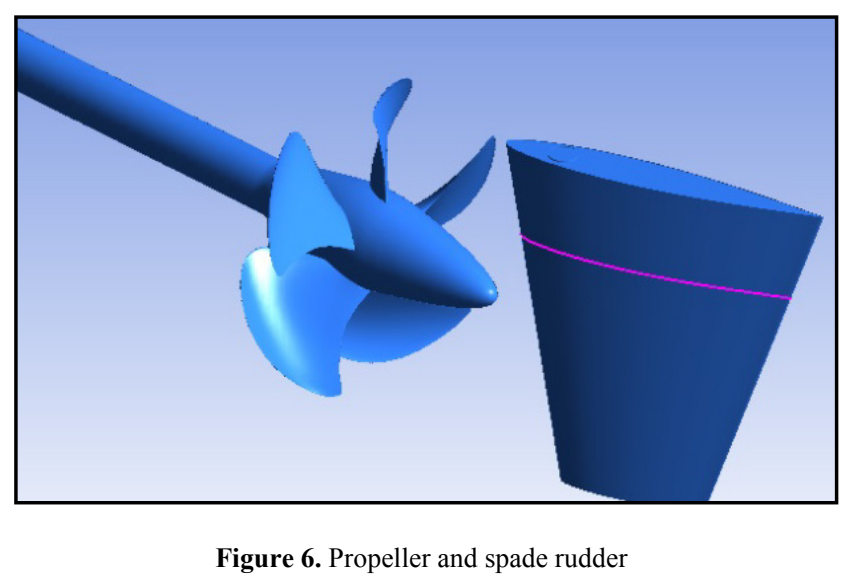

When the rudder is located behind the propeller (distance from the propeller to rudder, 0.25D) the propeller characteristics with and without rudder is shown in Figure 7 . Here the rudder angle is zero $\left(\delta_{R}=0\right)$. As shown in this figure, the thrust is almost the same with and without rudder, except at $\mathrm{J}=0.2$ that is increased with rudder.

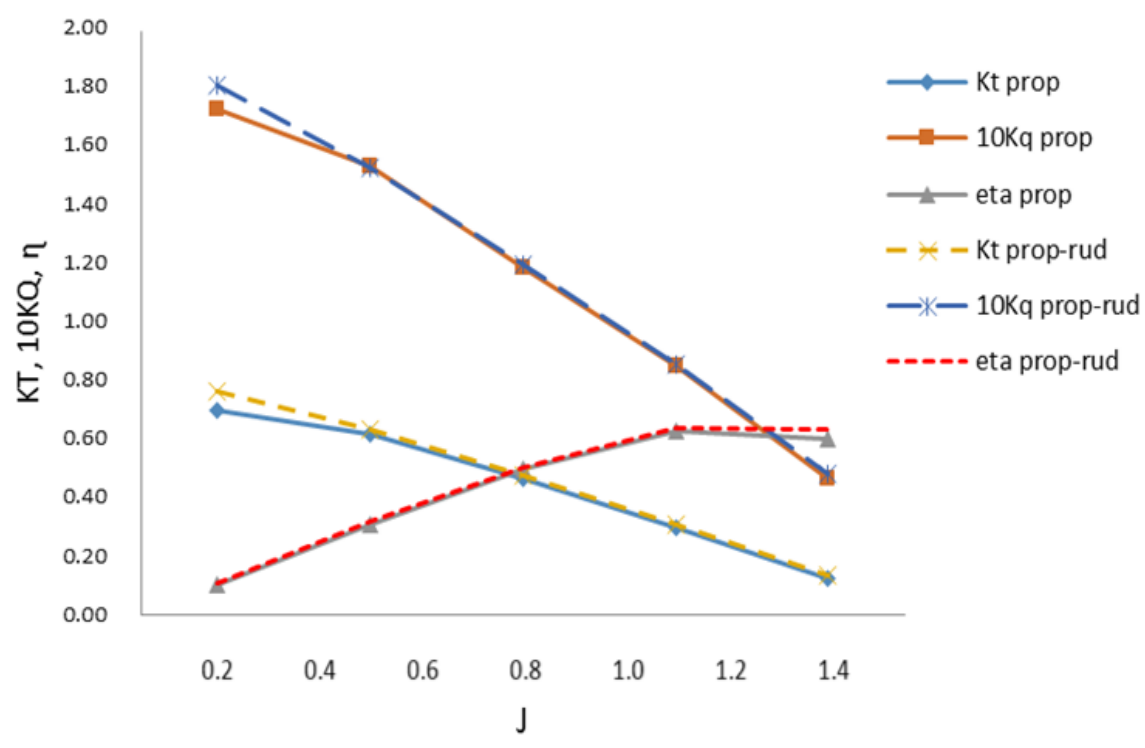

Figure 7. Propeller characteristics with and without rudder $\left(\delta_{R}=0\right)$ 


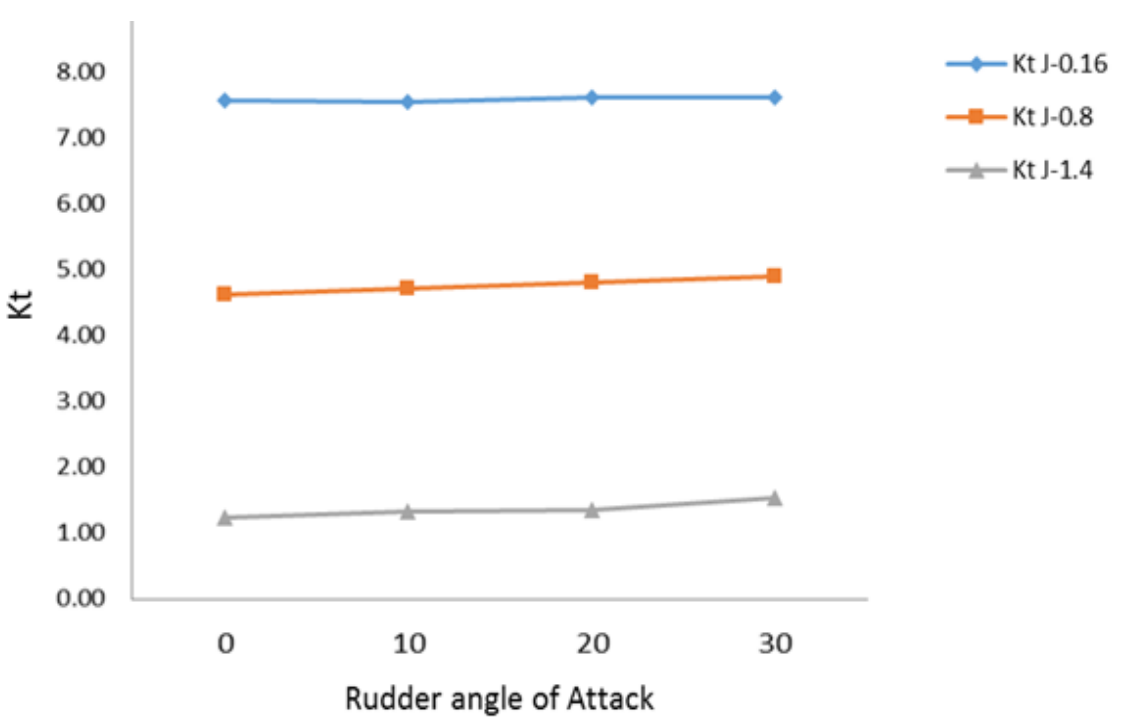

Figure 8. Thrust coefficient of the propeller against rudder angle at three advance coefficients

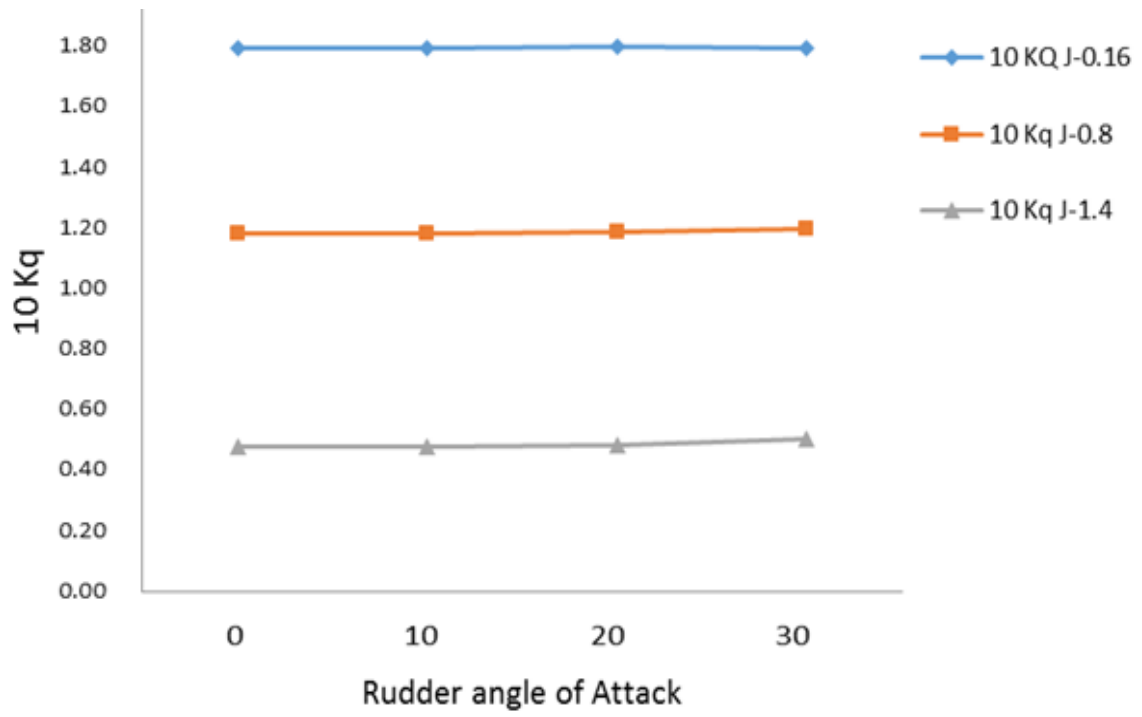

Figure 9. Torque coefficient of the propeller against rudder angle at three advance coefficients

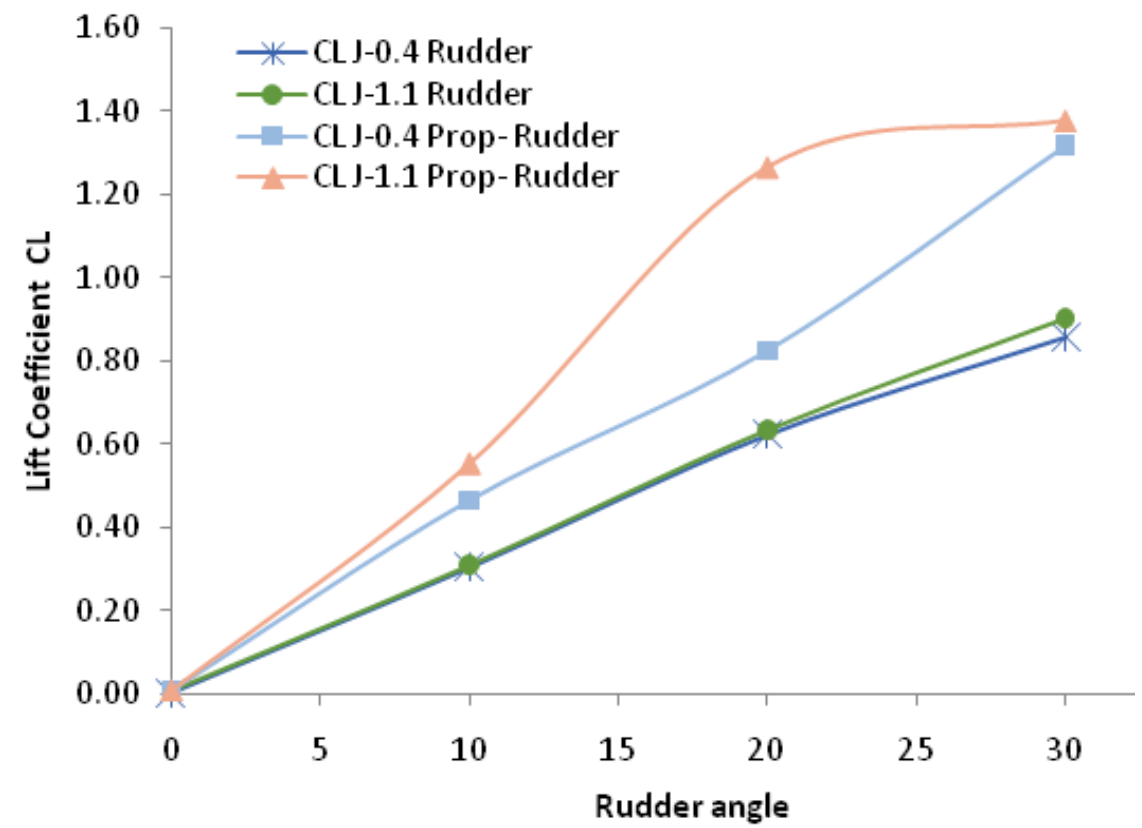

Figure 10. Lift coefficient of the rudder with and without propeller $(\mathrm{J}=0.4, \mathrm{~J}=1.1)$. 


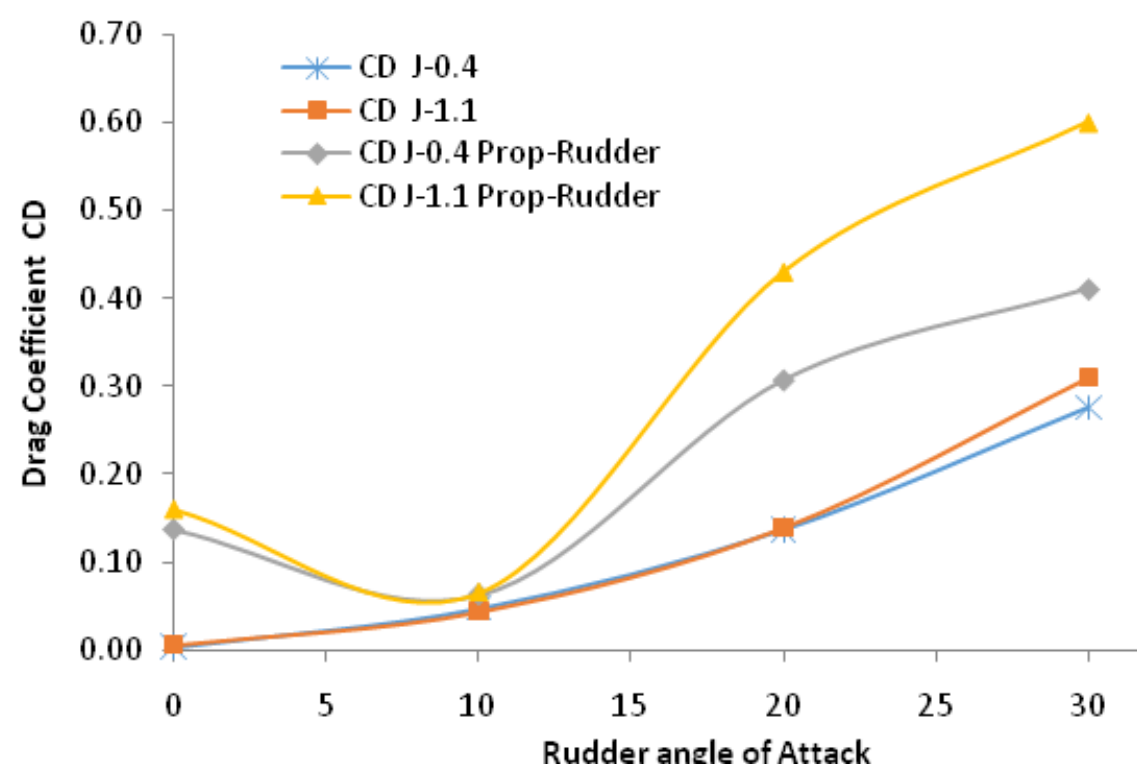

Figure 11. Drag coefficient of the rudder with and without propeller $(\mathrm{J}=0.4, \mathrm{~J}=1.1)$.

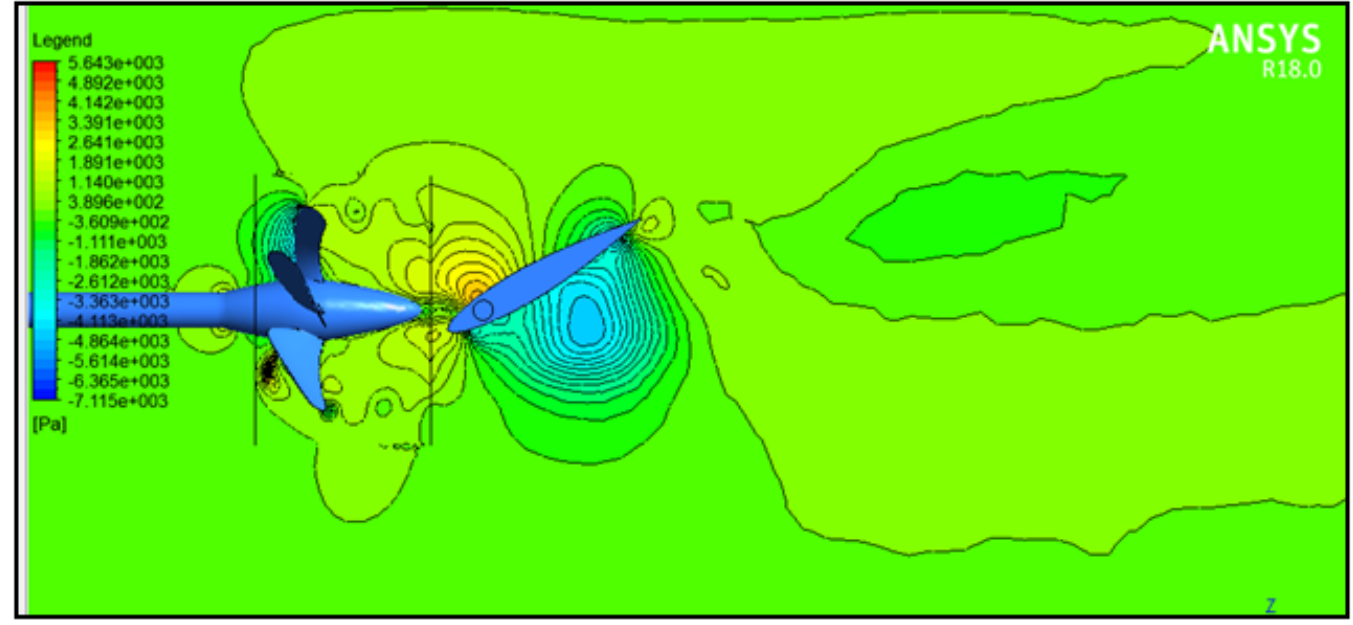

(A)

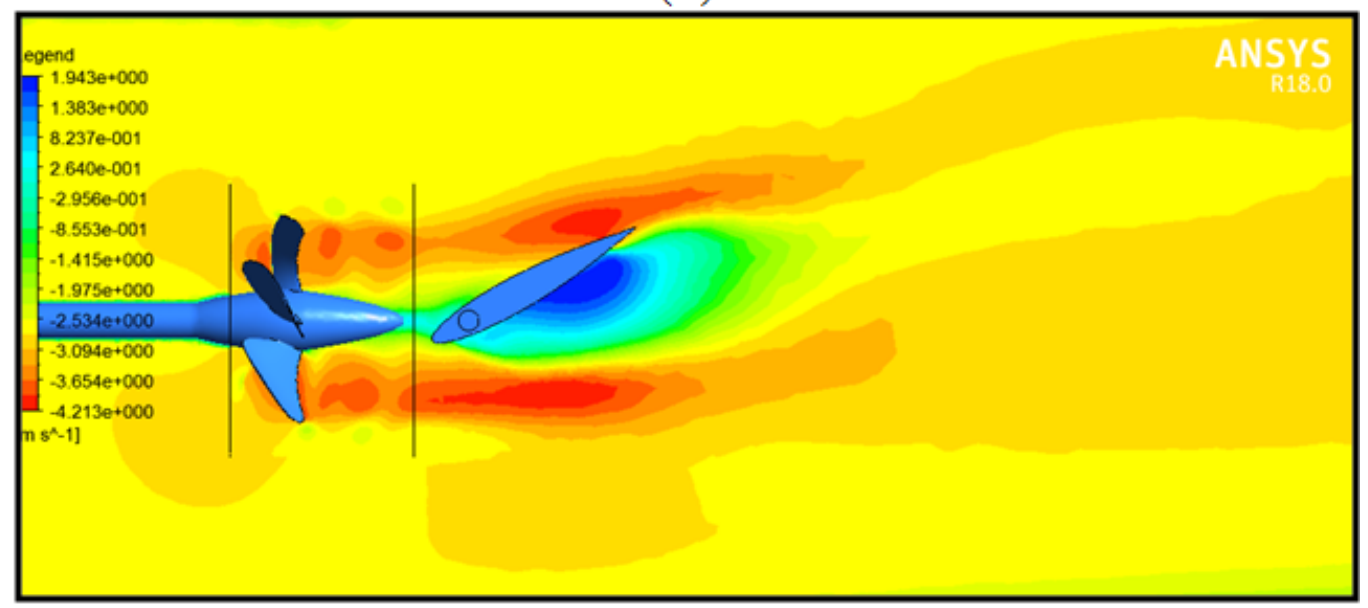

(B)

Figure 12. (A) Pressure contour and (B) velocity contour $\left(\mathrm{J}=1.1, \boldsymbol{\delta}_{\boldsymbol{R}}=\mathbf{3 0}\right)$

Figure 8 and Figure 9 show the thrust and torque of the propeller against rudder angles at three advance coefficients $(\mathrm{J}=0.16,0.8$ and 1.4$)$. It is observed that both thrust and torque are very slightly increased.

Rudder lift and drag coefficients $\left(\mathrm{C}_{\mathrm{L}}\right.$ and $\left.\mathrm{C}_{\mathrm{D}}\right)$ against rudder angles are presented at Figure 10 and Figure 11 at two advance coefficients $(\mathrm{J}=0.4$ and 1.1$)$ with and without propeller. When the rudder is located behind the propeller the lift and drag are more than in case of without propeller. It is may be due to the propeller induced velocities.

Pressure and velocity contour are presented at $\mathrm{J}=1.1$ and $\delta_{R}=30$ in Figure 12. The high pressure is found at face side of propeller and in one side of the rudder. 


\section{Conclusion}

In this study, hydrodynamic characteristics of propeller and rudder at various conditions are calculated. Based on the numerical results, the following conclusions may be drawn:

- The present numerical results of the propeller characteristics are well agreed with the experimental data at high at low advance coefficients. The maximum relative error for the thrust coefficient is less than $10 \%$ and for the torque is less than $9 \%$ at low advance coefficients. Average error is less than 5\%.

- Effect of the rudder on the propeller characteristics is caused to increase slightly

- Rudder lift and drag are increased when it is located behind the propeller. So, it may be concluded that rudder effect on the propeller is very small while the propeller on the rudder lift and drag is significant.

\section{References}

[1] Kim, H.T. and Stern, F. Viscous flow around a propeller-shaft configuration with infinite pitch rectangular blades, $\mathrm{J}$ of Propulsion and Power, 6(4), 1990, 434-444.

[2] Stanier, M.J. Investigation into propeller skew using a 'RANS' code. Part 1: Model scale. International Shipbuilding Progress, 45(443), 1998, 237-251.

[3] Stanier, M.J. Investigation into propeller skew using a 'RANS' code. Part 2: Scale effects. Int Shipbuilding Progress, 45(443), 1998, 253-265.

[4] Molland, A. Turnock, S.R. Marine Rudders and Control Surfaces. $1^{\text {st }}$ Ed, Butterworth-Heinemann, Oxford, UK, 2007.

[5] Hakan Ozdemira Y, Bayraktara S., Yılmaza T., Flow field analysis of a rudder by using computational fluid dynamics. $5^{\text {th }}$ Int Adv Tech Symp (IATS'09), May 13-15, Karabuk, Turkey, 2009.

[6] Young Y.L, Brizzolara S, Numerical and physical investigation of a surface-piercing hydrofoil. Third International Symposium on Marine Propulsors SMP'13, Tasmania, Australia, 2013.

[7] Ueno M, Tsukada Y, Kitagawa Y, Rudder effectiveness correction for scale model ship testing. NMRI, Tokyo 181-0004 Japan, 2012.

[8] Krasilnikov V, Ponkratov D, Crepier P, A Numerical study on the characteristics of the system propeller and rudder at low speed operation, 2 ${ }^{\text {nd }}$ SMP'11, Hamburg, Germany, June 2011.

[9] Mascio A.D, Dubbioso G, Muscari R, Felli M., CFD analysis of propeller-rudder interaction, Proc $25^{\text {th }}$ Int Ocean and Polar Eng Conf, Hawaii, USA, June 21-26, 2015, 946-950, 2015.

[10] Muscaria R., Dubbiosoa G., Vivianib M., Mascioc A.D., Analysis of the asymmetric behavior of propeller-rudder system of twin screw ships by CFD, 143(1), 2017, 269-281.

[11] He L., Kinnas S.A., Numerical simulation of unsteady propeller/rudder interaction, Int $\mathrm{J}$ of $\mathrm{Na}$ Arch and Oc Eng, 9(6), 2017, 677-692.

[12] Ghassemi H., Ghadimi P., Computational hydrodynamic analysis of the propeller-rudder and the AZIPOD systems, Ocean Eng 35(1), 2008, 117-130.

[13] Ghassemi H., Iranmanesh $\mathrm{M}$, Comparison of hydrodynamic characteristics on two ship propulsors (PRS And Azipod), Iranian J. of Sci Tech 32(4), 2008.

[14] Ghassemi, H., Allafchi F., A new implementation of vortex lattice method applied to the hydrodynamic performance of the propellerrudder, J Ocean, Mech and Aerospace, 16, 2015.

[15] Ghassemi H., Zakerdoost H., Ship hull-propeller system optimization based on the multi-objective evolutionary algorithm, Proc of the Ins Mech Engineers, Part C: J. Mech Eng Sci, 231(1), 2017, 175-192.

[16] Zakerdoost H., Ghassemi H., Hydrodynamic multidisciplinary optimization of a container ship and its propeller using comprehensive HPSOP code, Scientific J Maritime Univ of Szczecin, 2018, 53(125), 48-56.

[17] Zakerdoost H., Ghassemi H., A multi-level optimization technique based on fuel consumption and energy index in early-stage ship design, Structural and Multidisciplinary Optimization, 1-22.

[18] Zakerdoost H., Ghassemi H., Hydrodynamic multidisciplinary optimization of a container ship and its propeller using comprehensive HPSOP code, Scientific J Maritime Univ of Szczecin, 2018, 53(125), 48-56. 